\title{
Vorwort von Fadumo Korn
}

Das Ritual der Beschneidung hat dazu geführt, dass sich Jahrtausende lang Mädchen und Frauen nicht unabhängig und frei entwickeln konnten.

„Ich erzähle ihnen mein persönliches Schicksal - von dem Tag, der mein Leben so verändert hat. Es war eines morgens ganz früh, als meine Mutter mich holte. Sie nahm mich mit, wusch mir das Gesicht und gab mir nichts zum Frühstück, was mich gewundert hat. Lediglich ein Schlückchen Tee habe ich bekommen. Wir verließen unser Dorf und liefen und liefen und liefen. Als der Morgen dämmerte, kamen wir an eine freie Lichtung, an eine kahle Wüste. Zwischen den Schirmakazien, die sowohl ganz niedrige Büsche waren als auch hohe elegante afrikanische Schirmakazien, haben wir uns in den heißen Sand hingesetzt und meine Mutter hat gesagt: wir warten hier auf jemanden.

Ich wusste nicht, was passieren wird, ahnte aber, dass nichts Gutes kommen wird. Mir war wirklich schlecht und ich hatte das Gefühl, mich übergeben zu müssen. Ich hatte Panikattacken, konnte nicht weglaufen, wollte aber auch keine Schande über meine Familie bringen. Wir warteten und kurz danach schälte sich aus der staubigen afrikanischen Landschaft eine Gestalt heraus. Diese Gestalt sah alt und gebrechlich aus. Dennoch erreichte uns die Frau mit energischen Schritten, obwohl der Oberkörper ziemlich gebeugt war und sie einen Buckel hatte.

Meine Angst war unerträglich. Meine Mutter hatte geahnt, dass ich vielleicht weglaufen könnte und hat mich am Arm gepackt, hat mich festgehalten und sie hat gesagt: alles wird gut, es passiert dir doch gar nichts. Die Frau, die auf mich zukam, sah alles andere als vertrauenserweckend aus. Sie sah alt aus, sie sah böse aus, sie hatte schmutzige Finger und Hände, die so rau waren wie Elefanten. Wie Steine sahen sie aus, grau und rissig. Und als ich diese Hände erblickte, wurde es mir eiskalt am Rücken. Ich hatte Gänsehaut und schwitzte gleichzeitig. In diesem Moment habe ich geahnt, dass nichts Gutes passieren wird.

Die Frau packte ihre Utensilien aus und breitete ein Tuch zur Vorbereitung für ihre sogenannte Operation aus. Sie hatte kein Wasser, um ihre Hände oder die Instrumente zu waschen. Sie packte eine Rasierklinge aus, legte sie auf das schmutzige Tuch, öffnete eine kleine Dose, in der eine schmierige schwarze Paste enthalten war. Sie hatte ein kleines Stöckchen dabei und einen Faden aus Sisal. Sie brach die Rasierklinge in zwei Hälften und steckte sie in das Stöckchen hinein. Das Stöckchen umwickelte sie oben und unten mit dem Faden und in der Mitte schaute die Rasierklinge heraus wie ein kleines Beil. Mir wurde klar, irgendetwas wird aus mir herausgeschnitten, aber ich wusste nicht was. Ich beobachtete diese ganze Zeremonie, die sie dort veranstaltete, mit wahnsinniger Genauigkeit. Schließlich deutete sie mir mich hinzulegen. Ich war natürlich stocksteif und habe mich geweigert. 
Vor lauter Schreck konnte ich mich nicht bewegen, ich konnte meine Augen nicht schließen, ich konnte nicht wegschauen, ich war gebannt vor Schreck, starr vom Schock. Und dann sagte meine Mutter, ich soll mich auf eine Wanne aus Leichtmetall setzen, die sie mitgebracht hatte. Ich setzte mich darauf und in dem Moment fielen sie über mich her. Meine Beine wurden auseinandergerissen, ich wurde nach hinten gezerrt und festgehalten. Mir wurde ein mit Leder umwickeltes Stöckchen quer in den Mund hineingeschoben, damit ich mir meine Zunge nicht abbeiße wie ich später herausgefunden habe.

Ich war von dem ersten Schnitt dermaßen überwältigt. Es sind Schmerzen, wie wenn man heiße Eisen in den Körper jagt, wie glühendes Metall fühlte sich das an. Ich kann mich noch genau daran erinnern, dass ich einen gurgelnden Schrei herausgebracht habe. Alles andere blieb in meinem Hals stecken. Ich sah den Himmel über mir, der vorhin so schön blau war, und der jetzt total grau wurde. Ich hatte das Gefühl, die Erde war stehen geblieben, die Vögel hörten auf zu singen, der Wind hörte auf zu wehen, die Bäume hatten die Bewegung ihrer Blätter eingestellt, es bewegte sich gar nichts mehr. Es rührte sich nichts, außer das Grauen in mir. Ich war nicht fähig zu fühlen, obwohl ich gleichzeitig alles hörte, sah und fühlte. Ich spürte eiskaltes Blut über mein Gesäß laufen. Eiskalt. Ich kann mich erinnern, dass ich versucht habe, meine Fingernägel in den Arm meiner Mutter zu vergraben und ich spürte, wie eine riesige Energie aus mir hinausstieg und in den Himmel verschwand. Ich spürte, wie mein Körper sich verabschiedete, wie mein Geist nicht mehr fähig war, dieses Elend auszuhalten und aus mir herausstieg. Ich sah mich selbst oben schwebend auf dieses Gemetzel herunterschauend.

Ich kann mich erinnern und ich kann hören, wie die schreckliche Frau ihre Stacheln und Dornen durch meine Schamlippen steckte. Ich kann das Quietschen bis heute hören, ich kann das Kratzen hören. Ich kann das Geschimpfe von ihr hören, als sie mir einen abgebrochenen Stachel aus meiner Schamlippe heraus fingern musste. Ich kann mich erinnern, wie sie mich beschimpft hat, aber ich war einfach nur ruhig. Ich hatte aufgegeben, mein Körper hatte aufgegeben, mein Geist hatte aufgegeben. Ich wartete auf mein Sterben. Aber ich starb nicht. Mein Körper entzündete sich, ich fiel in ein Koma, ich hatte unendlich hohes Fieber. Mein Körper brannte und pochte und stach und ich betete zum lieben Gott, solange ich noch die Schmerzen spürte, lass mich sterben, ich halte es nicht aus. Es wäre gut, wenn ich jetzt gehen könnte, denn jetzt bin ich rein. Ich darf gehen, ich darf sterben, weil ich dann sowieso in das Paradies komme.

Früher hat man uns erklärt, dass alle Mädchen, die ihre Klitoris haben, die nicht beschnitten sind, unrein sind. Wenn sie sterben, kommen sie direkt in die Hölle. Kann man sich vorstellen, dass man so etwas einem kleinen Kind sagt? An dem Tag, als ich beschnitten worden bin, ich glaube es war an einem Mittwoch, konnte ich bis zum nächsten Tag nicht urinieren. Die ganze Flüssigkeit, das ganze Blut, die ganzen Sekrete konnten nicht abfließen. Ich wäre so gerne gestorben. Hauptsache, die ganzen Schmerzen hören auf.“ 